\title{
Metatarsophalangeal Joint 2
}

National Cancer Institute

\section{Source}

National Cancer Institute. Metatarsophalangeal/oint 2. NCI Thesaurus. Code C102322.

A condyloid synovial joint within the second digit of the foot connecting metatarsal with the proximal phalanx. 